\title{
European Surgical Research: The Future Is Bright!
}

\author{
Frank J.M.F. Dor ${ }^{a, b} \quad$ Brigitte Vollmar \\ a Imperial College Renal and Transplant Centre, Hammersmith Hospital, Imperial College Healthcare NHS Trust, \\ London, UK; ${ }^{b}$ Department of Surgery and Cancer, Imperial College London, London, UK; ' University Medicine \\ Rostock, Institute for Experimental Surgery, Rostock, Germany
}

European, Surgical, Research. Three powerful words that characterise our journal well. With fresh energy and dedication, we are delighted that we have started to work together since last year as joint editors-in-chief. In the past year, we have welcomed new top class Associate Editors and Editorial Board members and have had a few inspiring meetings to brainstorm on how to improve the journal from content to outreach.

European Surgical Research reflects a large scope; from basic science and experimental surgery to translation into clinical practice, innovation, and evidence-based medicine. The journal covers all major surgical specialties, and we are aiming for high-quality research that will likely have impact in the field. Recently, we have seen good examples of these papers represented as Editors' Choice papers on the website.

The good news is that we feel very much supported by our excellent editorial team and have seen a significant increase in submissions with $300 \%$. Unfortunately, this means that we will have to reject papers that do not reach enough priority for publication in European Surgical Research after editorial review or even before peer review, and sometimes papers even have to be rejected after several revisions if they fail to pass the quality mark in the end.

karger@karger.com www.karger.com/esr

Karger"
(C) 2022 The Author(s)

Published by S. Karger AG, Basel

This is an Open Access article licensed under the Creative Commons Attribution-NonCommercial-4.0 International License (CC BY-NC) (http://www.karger.com/Services/OpenAccessLicense), applicable to the online version of the article only. Usage and distribution for commercial purposes requires written permission.
In recent years, the impact factor of the journal has not gone up, and has remained stable, but we wish to think beyond the impact factor alone. The impact factor is one way of measuring how a journal can influence the field (and we certainly aim for it to increase again), but we know from experience and previous literature that in 2022 , the impact of a journal and individual papers also comes through visibility and the way publications are shared. No longer a journal lands on a desk only, no longer papers are photocopied and sent around to those interested by air mail. We firmly believe a journal should make papers available as widely as possible and shared in the European Surgical community and beyond.

We wish to make a difference with Early View publications which is a feature now available since a few months, to make every accepted paper available online as soon as possible as citeable item, which is important to many authors that submit their work to us. We offer Open Access publication, and much of the content is made Free Access based on editorial choice. On top of this, we are working on social media strategies to widen the impact of individual papers for our authors and the journal.

We are very excited to have launched Special Topic Issues, the first one on severity assessment in animal-based research, and a second one is in development and will be 
about one of the most successful innovative strategies in surgery that is making a huge clinical impact in organ transplantation and beyond. Please do send us your suggestions for forthcoming special topic issues and engage with the journal.

We firmly believe European Surgical Research can and will be one of the leading surgical journals with a focus on Research ranging from the laboratory to randomised clinical trials and futuristic applications. Submit your best work, and we will make sure that, once accepted, it will be visible rapidly in the wider international surgical community.

The future is bright, and surgical research will remain at the cornerstone of medicine. Surgeons and surgical researchers have always had a massive impact in medicine and society, and as European Surgical Research we wish to contribute to this as an important platform for highquality publications that are impactful and meaningful.

\section{Conflict of Interest Statement}

FJMFD has received consultancy fees and speaker fees from Astellas, Sandoz, Chiesi, Baxter, and TEVA. There is no conflict of interest for B.V.

\section{Funding Sources}

Grants of B.V. are funded by the German Research Foundation (DFG). 